\title{
Ivacaftor in cystic fibrosis adults: Czech experience with six years of follow-up
}

\author{
Libor Fila ${ }^{\mathrm{a}, \mathrm{b}}$, Lucie Valentova Bartakovaa, ${ }^{\mathrm{a}, \mathrm{b}}$, Alzbeta Grandcourtovaa, ${ }^{\mathrm{a}, \mathrm{b}}$, Miloslav Marel ${ }^{\mathrm{a}}$, Radovan Drnek ${ }^{\mathrm{c}}$, Alena Bilkova ${ }^{\mathrm{b}, \mathrm{d}}$, \\ Milan Macek Jr. ${ }^{\text {bee }}$, Pavel Drevinek ${ }^{\text {b,f }}$
}

\begin{abstract}
Aims. Ivacaftor is a revolutionary treatment option for cystic fibrosis (CF) patients with G551D and other gating mutations. The aim of this study was to evaluate the clinical status of patients on ivacaftor who were followed for up to 6 years together with an evaluation of ivacaftor therapy in one patient with an initial $\mathrm{FEV}_{1}$ less than $40 \%$ of predicted value. Methods. Data on development of clinical status and sinopulmonary-related therapies were obtained from patient health records during ivacaftor treatment lasting for up to six years and were compared with an equivalent period before ivacaftor administration.

Results. Five CF adults with a median age 28.6 years (range $21.4-35.6$ years) with median FEV $15 \%$ pred. (range $16-85 \%$ pred.) were included in the study. Four subjects were also participants in the STRIVE and PERSIST studies. Altogether, twenty-four patient-years of ivacaftor treatment were analyzed. The median FEV ${ }_{1}$ decline per year decreased from -4.5 to $-0.9 \%$ pred. $(P=0.043)$. Reduction in number of days on antibiotic treatment and hospital stays was $21 \%(P<0.001)$ and $75 \%(P=0.003)$, respectively. Improvement and stabilization of lung function was observed for up to six years of treatment. In a patient with severe airway obstruction, an increase in the FEV 1 value ( $30.4 \%$ from baseline) was documented during the first twelve months of treatment.

Conclusion. Ivacaftor therapy resulted in improved and stabilized lung function in up to six years of treatment with a reduction in number of days on antibiotic treatment and hospital stays. Its efficiency was also displayed in a patient with severe airway obstruction.
\end{abstract}

Key words: cystic fibrosis, adults, lung disease, ivacaftor

Received: February 2, 2016; Accepted: May 3, 2016; Available online: May 25, 2016 http://dx.doi.org/10.5507/bp.2016.029

${ }^{a}$ Department of Pneumology, $2^{\text {nd }}$ Faculty of Medicine, Charles University in Prague and University Hospital Motol, Prague, Czech Republic ${ }^{b}$ Cystic Fibrosis Centre, University Hospital Motol, Prague, Czech Republic 'Division of Health Insurance, University Hospital Motol, Prague, Czech Republic

${ }^{d}$ Department of Pediatrics, $2^{\text {nd }}$ Faculty of Medicine, Charles University in Prague and University Hospital Motol, Prague, Czech Republic ${ }^{e}$ Department of Biology and Medical Genetics, $2^{\text {nd }}$ Faculty of Medicine, Charles University in Prague and University Hospital Motol, Prague, Czech Republic

${ }^{f}$ Department of Medical Microbiology, $2^{\text {nd }}$ Faculty of Medicine, Charles University in Prague and University Hospital Motol, Prague, Czech Republic

Corresponding author: Libor Fila, e-mail: libor.fila@fnmotol.cz

\section{INTRODUCTION}

Cystic fibrosis $(\mathrm{CF})$ is the most common inherited disease leading to premature death in Caucasians. CF is caused by mutations in the cystic fibrosis transmembrane regulator (CFTR) gene which encodes the CFTR protein. The CFTR protein is an epithelial ion channel participating in the regulation of water and salt content of exocrine gland secretions. Dysfunction of the CFTR protein leads to multiorgan disease involving sweat glands and the respiratory, digestive, and reproductive systems ${ }^{1}$. Today, more than 2000 mutations of the CFTR gene have been identified ${ }^{2}$. These mutations can be divided into six classes according to their effect on the CFTR protein. For example, the most common mutation, which is termed F508del, is categorized as a class II defect. In this class, the CFTR protein is recognized as misfolded and is degraded shortly after synthesis. Another mutation, named G551D, results in disordered regulation of CFTR protein (class III)(ref. $\left.{ }^{3}\right)$. Drugs targeting the underlying defects in the cellular processing and chloride channel function (i.e.
CFTR modulators) can be divided into two groups. CFTR correctors are principally targeted at cellular misprocessing (e.g. in F508del mutation), whereas CFTR potentiators are intended to restore chloride channel activity (e.g. in G551D mutation) (ref. ${ }^{4}$ ).

Before 2012, CF therapy consisted of symptomatic treatment of the consequences associated with CFTR protein dysfunction, e.g. pancreatic enzyme supplementation, chest physiotherapy, and antibiotics. This situation changed on the $31^{\text {st }}$ of January 2012 when ivacaftor was approved in the United States, for patients with the G551D mutation 5 . In clinical studies, ivacaftor administration led to improvement in pulmonary function and nutritional status and to lower sweat chloride concentrations. Fewer hospital stays, pulmonary exacerbations and antibiotic use were also observed ${ }^{6,7}$.

However, this revolutionary drug faces one very serious drawback. The costs for ivacaftor could be as high as US $\$ 300,000$ per one year of treatment ${ }^{8}$. The total additional lifetime costs for all eligible CF patients in England ranged from $£ 438,000,000$ to $£ 479,000,000$, as was mod- 
elled by Whiting et al. ${ }^{9}$ The lifetime cost for standard care only was $£ 72,000,000$ in the same model. For such an expensive drug, especially in situations of predictable lifelong treatment, the benefit to patients should be clearly established.

Ivacaftor showed efficiency in clinical studies lasting from 24 to 96 weeks in subjects with a forced expiratory volume in the first second $\left(\mathrm{FEV}_{1}\right)$ greater than $40 \%$ of the predicted value. Long-term efficiency together with usefulness in those with severe airway obstruction has not been extensively studied.

To answer the above questions, we evaluated the clinical status of subjects who were participating in the STRIVE (NCT00909532) and PERSIST (NCT01117012) studies $^{10,11}$ and were followed for up to 6 years. In this paper we report on the follow-up data together with an evaluation of ivacaftor therapy in one patient with an initial $\mathrm{FEV}_{1}$ less than $40 \%$ of predicted value.

\section{MATERIALS AND METHODS}

Five adult patients with CF and G551D mutation being treated at the Prague CF centre at the Motol Faculty Hospital, were included in the study. Four of them were also participants of the STRIVE and PERSIST studies. The fifth patient had severe airway obstruction $(<40 \%$ of the predicted value). Outside of clinical studies, the drug was supplied on the basis of the Patient Access Program or $\S 16$ of Act No. 48/1997 Coll.

Demographic parameters (sex and age), CFTR genotype, sweat chloride concentration, pulmonary function, airway infection, nutritional status and other extrapulmonary manifestations at the initiation of ivacaftor treatment were obtained from patient records. Changes in sweat chloride concentration, pulmonary function and nutritional status, together with the number of treatments for sinopulmonary symptoms, days on antibiotic and stays in hospital during ivacaftor treatment were also taken from patient records and compared with the situation during an equivalent time period before ivacaftor initiation.

Statistical analysis was performed using Statistica $8 \mathrm{Cz}$ (StatSoft, Czech Republic) statistical software. Data are presented as the median and range. The Wilcoxon signedrank test and $\chi^{2}$ test were used for analysis. A $P$-value $<0.05$ was considered to be statistically significant.

\section{RESULTS}

Baseline characteristics of patients before starting ivacaftor treatment are provided in Table 1. Three patients received ivacaftor in both studies, while one patient only recieved ivacaftor in the PERSIST study (subjects were unblinded after the end of the STRIVE study). Altogether, 24 patient-years of ivacaftor treatment were analyzed.

Changes in the lung function of participants in the STRIVE and PERSIST studies and in a patient with severe airway obstruction are presented in Fig. 1 and 2, respectively.

One-year $\mathrm{FEV}_{1}$ decline before and on ivacaftor treatment differ significantly in the median -4.5 (range -7.4 to -0.6 ) vs. -0.9 (range -1.2 to 0.6 ) $\%$ of the predicted value ( $P=0.043$; Wilcoxon signed-rank test). Most patients experienced an increase in $\mathrm{FEV}_{1}$ (after 8 weeks) and an increase in body weight (after 48 weeks) on ivacaftor: median 330 (range $160-730) \mathrm{mL}(P=0.043$; Wilcoxon signed-rank test) and 1.0 (range $0.0-5.5) \mathrm{kg}$ ( $P=0.068$; Wilcoxon signed-rank test), respectively. The improvement of nutritional status in the participants in the STRIVE and PERSIST studies persisted for five years of follow-up. The median increase in body weight was 2.0 (range 1.0 - 6.0) kg. Changes in sinopulmonary-related treatment are in shown in Table 2.

Table 1. Characteristic of patients.

\begin{tabular}{|c|c|c|c|c|c|c|c|c|}
\hline \multirow{2}{*}{$\begin{array}{l}\text { Patient } \\
\text { (sex; age) }\end{array}$} & \multirow{2}{*}{$\begin{array}{l}\text { Second } \\
\text { mutation }\end{array}$} & \multirow{2}{*}{$\begin{array}{c}\mathrm{FEV}_{1} \\
\text { (\% pred.) }\end{array}$} & \multirow{2}{*}{$\begin{array}{l}\text { Airway } \\
\text { infection }\end{array}$} & \multirow{2}{*}{$\begin{array}{c}\text { BMI } \\
\left(\mathrm{kg} / \mathrm{m}^{2}\right)\end{array}$} & \multirow{2}{*}{$\begin{array}{l}\text { Extra- pulmonary } \\
\text { manifestation }\end{array}$} & \multicolumn{2}{|c|}{$\begin{array}{l}\text { Ivacaftor treatment } \\
\text { in clinical studies }\end{array}$} & \multirow{2}{*}{$\begin{array}{c}\text { Treatment } \\
\text { duration } \\
\text { (years) }\end{array}$} \\
\hline & & & & & & STRIVE & PERSIST & \\
\hline F; 35.6 & N1303K & 44 & PA & 21.5 & PI & + & + & 6 \\
\hline M; 28.6 & R553X & 85 & NN & 26.1 & PI & + & + & 6 \\
\hline $\mathrm{F} ; 25.8$ & F508del & 45 & PA & 19.3 & PI; DM & + & + & 6 \\
\hline M; 21.4 & F508del & 53 & PA & 21.5 & PI; DM; LD & - & + & 5 \\
\hline M; 29.3 & N1303K & 16 & $\mathrm{BCc}$ & 18.0 & PI & - & - & 1 \\
\hline
\end{tabular}

$\mathrm{M}=$ male; $\mathrm{F}=$ female; $\mathrm{PA}=$ Pseudomonas aeruginosa $; \mathrm{BCc}=$ Burkholderia cepacia complex; $\mathrm{NN}=$ without $P$. aeruginosa or B. cepacia complex; $\mathrm{PI}=$ pancreatic insufficiency; $\mathrm{DM}=$ diabetes mellitus; $\mathrm{LD}=$ liver disease; $\mathrm{FEV}_{1}=$ forced expiratory volume in the first second; $\mathrm{BMI}=$ body mass index.

Table 2. Change in sinopulmonary-related treatment.

\begin{tabular}{|c|c|c|c|c|}
\hline Parameter & $\begin{array}{l}\text { Before ivacaftor } \\
\text { (per patient-year) }\end{array}$ & $\begin{array}{c}\text { On ivacaftor } \\
\text { (per patient-year) }\end{array}$ & $\begin{array}{c}\text { Reduction rate } \\
(\%)\end{array}$ & $\begin{array}{c}P \\
\left(\chi^{2} \text {-test }\right)\end{array}$ \\
\hline Treatment for sinopulmonary symptoms & 3.0 & 2.3 & 23.6 & n.s. \\
\hline Days on ATB & 48.8 & 38.6 & 21.0 & $<0.001$ \\
\hline Hospital stays & 0.58 & 0.13 & 78.6 & 0.003 \\
\hline
\end{tabular}

ATB = antibiotic; n.s. = not significant 


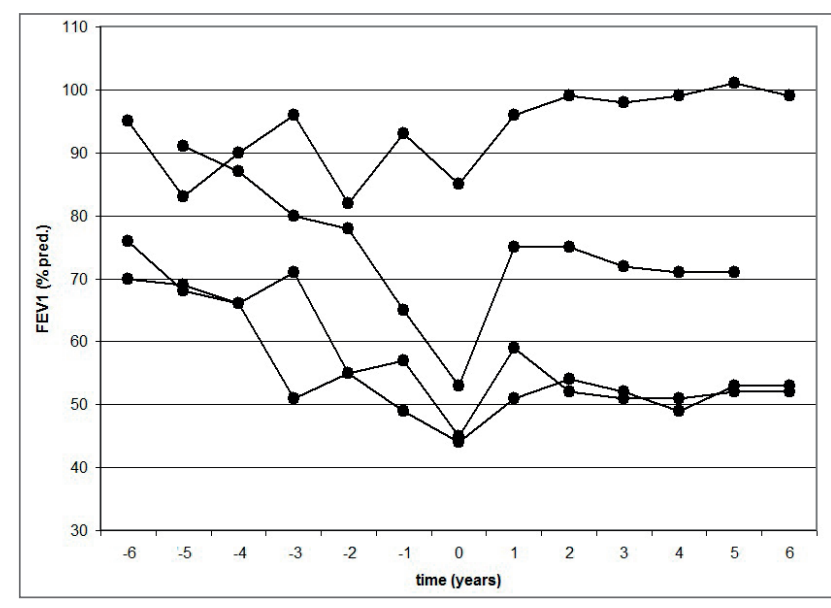

Fig. 1. Change in $\mathrm{FEV}_{1}$ in the STRIVE and PERSIST study participants.

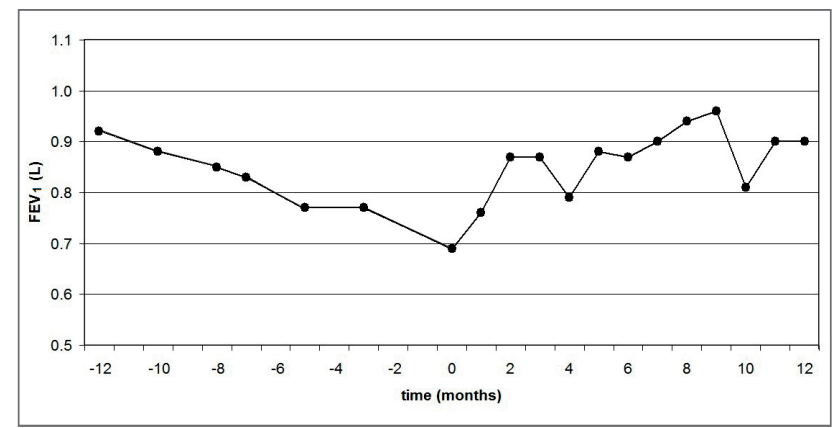

Fig. 2. Change in $\mathrm{FEV}_{1}$ in a patient with severe airway obstruction.

Sweat chloride concentration decreased in all patients. The median of these values before and on ivacaftor treatment was 104 (range 86-119) mmol/L and 52 (range 1958) $\mathrm{mmol} / \mathrm{L}$, respectively.

\section{DISCUSSION}

The CFTR gene was discovered in 1989 and gene therapy for CF was expected to be available shortly thereafter. Unfortunately, this goal has yet to be achieved. Instead, another therapy using CFTR protein modulators - correctors and potentiators - has become a clinical reality 23 years after the discovery of the CFTR gene. Ivacaftor (previously VX-770) is a CFTR protein potentiator, one of a group of drugs that improve the function of the CFTR protein in the epithelial cell membranes ${ }^{12}$.

In clinical studies, ivacaftor has improved pulmonary function and nutritional status and reduced the number of pulmonary exacerbations, antibiotic use and number of hospital stays. Additionally, improvement in quality of life, mucociliary clearance, gastrointestinal $\mathrm{pH}$, higher levels of exhaled nitric oxide, lower doses of insulin (in diabetics), and fewer infection with Pseudomonas aeruginosa have been observed during ivacaftor treatment ${ }^{13-17}$. Lower sweat chloride concentration has also been clearly documented and the sweat test can be utilized as a marker of compliance with ivacaftor therapy ${ }^{18}$.
When the results of the STRIVE and PERSIST studies are combined, current clinical evidence has documented the efficiency of ivacaftor for up to three years of treatment ${ }^{19}$. Our study showed consistent improvement and stabilization of lung function in a small group of CF adults treated with ivacaftor for up to six years. During this period, less need for antibiotic and inpatient treatment was also demonstrated. Our results are in accordance with previously published papers and show that even very longterm treatment with ivacaftor is meaningful.

Another potential use for ivacaftor treatment involves patients with severe airway obstruction. This condition was not included in the above mentioned clinical studies. There are some papers describing case reports or small groups of severe airway obstruction patients who profited from ivacaftor therapy ${ }^{20,21}$. However, the response to treatment appeared to be inconsistent ${ }^{22}$. In our case report, we described a patient with an initial $\mathrm{FEV}_{1}$ that was only $16 \%$ of the predicted value. We observed improvement in lung function within the first nine months of treatment, reaching an $\mathrm{FEV}_{1}$ that was $22 \%$ of the predicted value, which represented a $39.1 \%$ increase from baseline, despite chronic $B$. cenocepacia ST-32 airway infection.

We now have effective medicine for CF patients with the G551D and other gating mutations. That is the good news. The bad news is that the drug is extremely expensive. Ivacaftor was approved by the European Medicines Agency on the 23 $3^{\text {rd }}$ July 2012 for clinical $\mathrm{use}^{23}$. In the Czech Republic, ivacaftor was registered as Kalydeco ${ }^{\circledR}$, however, today it is still without established payment plan from the state health insurance system. The administrative procedure to determinate the appropriate payment from the state health insurance started in June 2013, and ended in April 2015 without any result. Another administrative procedure started in May 2015, but only the preliminary task of "obtaining documents" is currently underway ${ }^{24}$. This is very unfortunate and disappointing progress, considering the potential benefits.

Currently, the only practical way for CF patients to obtain this medication, is through the Patient Access Program for those who participated in the STRIVE and PROGRESS studies and those with severe airway obstruction. Another possibility is the use of $\S 16$ of Act No. 48/1997 Coll., which is not optimal for this purpose because not all health insurance companies accept this payment method (not to mention the exhausting administrative process associated with it).

We hope, that the convincing results of our study will contribute to a timely and positive decision from the regulatory authorities regarding payment for ivacaftor by the health insurance system of the Czech Republic.

\section{CONCLUSION}

Our results show the sustained efficiency of ivacaftor on pulmonary function for treatment periods up to six years. We also noted a marked reduction in antibiotic use and hospital stays. Short-term improvement of lung 
function was also observed in one patient with very severe airway obstruction.

Acknowledgement: This work was supported by projects of Ministry of Health of the Czech Republic 00064203, COST-LD14073, NF-CZ11-PDP-3-003-2014 and CZ.2.16/3.1.00/24022 OPPK. We would like to thank the company Vertex Pharmaceuticals for ivacaftor supplies to CF patients from the STRIVE and PERSIST studies. Ivacaftor treatment for the patient with severe airway obstruction came via the Patient Access Program. We would also like to thank all patients involved in this study.

Author contributions: LF, MM Jr., PD: conception and design of the study; LF, LBV, AG, AB acquisition of the data; LF, MM, RD, PD: analysis and interpretation of the data; LF, MM Jr., PD: revision of the manuscript; all authors: drafting and final approval.

Conflict of interest statement: LF, AB, MM Jr. and PD report personal fees from Vertex Pharmaceuticals. The remaining authors do not have any conflict of interest that could influence the content or processing of this manuscript.

\section{REFERENCES}

1. Ratjen F, Döring G. Cystic fibrosis. Lancet 2003;361(9358):681-9. doi: 10.1016/S0140-6736(03)12567-6

2. Available at: http://www.genet.sickkids.on.ca/cftr/StatisticsPage html. Accessed the $15^{\text {th }}$ January 2016.

3. Rowe SM, Miller S, Sorscher EJ. Cystic fibrosis. N Engl J Med 2005;352(19):1992-2001. doi: 10.1056/NEJMra043184

4. Rowe SM, Verkman AS. Cystic fibrosis transmembrane regulator correctors and potentiators. Cold Spring Harb Perspect Med 2013;3(7). pii: a009761. doi: 10.1101/cshperspect.a009761

5. Available at: http://www.fda.gov/NewsEvents/Newsroom/ PressAnnouncements/ucm289633.htm. Accessed the $15^{\text {th }}$ January 2016.

6. Ramsey BW, Davies J, McElvaney NG, Tullis E, Bell SC, Dřevínek $P_{\text {, }}$ Griese M, McKone EF, Wainwright CE, Konstan MW, Moss R, Ratjen F, Sermet-Gaudelus I, Rowe SM, Dong Q, Rodriguez S, Yen K, Ordoñez C, Elborn JS; VX08-770-102 Study Group. A CFTR potentiator in patients with cystic fibrosis and the G551D mutation. N Engl J Med 2011;365(18):1663-72. doi: 10.1056/NEJMoa1105185

7. McKone EF, Borowitz D, Drevinek P, Griese M, Konstan MW, Wainwright C, Ratjen F, Sermet-Gaudelus I, Plant B, Munck A, Jiang Y, Gilmartin G, Davies JC; VX08-770-105 (PERSIST) Study Group. Longterm safety and efficacy of ivacaftor in patients with cystic fibrosis who have the Gly551Asp-CFTR mutation: a phase 3, open-label extension study (PERSIST). Lancet Respir Med 2014;2(11):902-10. doi: 10.1016/S2213-2600(14)70218-8

8. Orenstein DM, O'Sullivan BP, Quinton PM. Cystic Fibrosis: Breakthrough Drugs at Break-the-Bank Prices. Glob Adv Health Med 2015;4(6):8-57. doi: 10.7453/gahmj.2015.123

9. Whiting $\mathrm{P}, \mathrm{Al} \mathrm{M}$, Burgers $\mathrm{L}$, Westwood $\mathrm{M}$, Ryder $\mathrm{S}$, Hoogendoorn $M$, Armstrong N, Allen A, Severens $H$, Kleijnen J. Ivacaftor for the treatment of patients with cystic fibrosis and the G551D mutation: a systematic review and cost-effectiveness analysis. Health Technol Assess 2014;18(18):1-106. doi: 10.3310/hta18180

10. Available at: https://clinicaltrials.gov/ct2/show/NCT00909532. Accessed the $15^{\text {th }}$ January 2016.

11. Available at: https://clinicaltrials.gov/ct2/show/NCT01117012. Accessed the $15^{\text {th }}$ January 2016.

12. Rogan MP, Stoltz DA, Hornick DB. Cystic fibrosis transmembrane conductance regulator intracellular processing, trafficking, and opportunities for mutation-specific treatment. Chest 2011;139(6):148090. doi: 10.1378/chest.10-2077

13. Quittner A, Suthoff E, Rendas-Baum R, Bayliss MS, Sermet-Gaudelus I, Castiglione B, Vera-Llonch M. Effect of ivacaftor treatment in patients with cystic fibrosis and the G551D-CFTR mutation: patient-reported outcomes in the STRIVE randomized, controlled trial. Health Qual Life Outcomes 2015;13:93. doi: 10.1186/s12955-015-0293-6

14. Rowe SM, Heltshe SL, Gonska T, Donaldson SH, Borowitz D, Gelfond D, Sagel SD, Khan U, Mayer-Hamblett N, Van Dalfsen JM, Joseloff E, Ramsey BW; GOAL Investigators of the Cystic Fibrosis Foundation Therapeutics Development Network. Clinical mechanism of the cystic fibrosis transmembrane conductance regulator potentiator ivacaftor in G551D-mediated cystic fibrosis. Am J Respir Crit Care Med 2014;190(2):175-84. doi: 10.1164/rccm.201404-0703OC

15. Grasemann H, Gonska T, Avolio J, Klingel M, Tullis E, Ratjen F. Effect of ivacaftor therapy on exhaled nitric oxide in patients with cystic fibrosis. J Cyst Fibros 2015;14(6):727-32. doi: 10.1016/j.jcf.2015.07.001

16. Bellin MD, Laguna T, Leschyshyn J, Regelmann W, Dunitz J, Billings J, Moran A. Insulin secretion improves in cystic fibrosis following ivacaftor correction of CFTR: a small pilot study. Pediatr Diabetes 2013;14(6):417-21. doi: 10.1111/pedi.12026

17. Heltshe SL, Mayer-Hamblett N, Burns JL, Khan U, Baines A, Ramsey BW, Rowe SM; GOAL (the G551D Observation-AL) Investigators of the Cystic Fibrosis Foundation Therapeutics Development Network. Pseudomonas aeruginosa in cystic fibrosis patients with G551DCFTR treated with ivacaftor. Clin Infect Dis 2015;60(5):703-12. doi: 10.1093/cid/ciu944

18. Accurso FJ, Van Goor F, Zha J, Stone AJ, Dong Q, Ordonez CL, Rowe SM, Clancy JP, Konstan MW, Hoch HE, Heltshe SL, Ramsey BW, Campbell PW, Ashlock MA. Sweat chloride as a biomarker of CFTR activity: proof of concept and ivacaftor clinical trial data. J Cyst Fibros 2014;13(2):139-47. doi: 10.1016/j.jcf.2013.09.007

19. Sawicki GS, McKone EF, Pasta DJ, Millar SJ, Wagener JS, Johnson CA, Konstan MW. Sustained Benefit from Ivacaftor Demonstrated by Combining Clinical Trial and Cystic Fibrosis Patient Registry Data. Am J Respir Crit Care Med 2015;192(7):836-42. doi: 10.1164/ rccm.201503-05780C

20. Polenakovik HM, Sanville B. The use of ivacaftor in an adult with severe lung disease due to cystic fibrosis ( $\triangle$ F508/G551D). J Cyst Fibros 2013;12(5):530-1. doi: 10.1016/j.jcf.2012.12.004

21. Barry PJ, Plant BJ, Nair A, Bicknell S, Simmonds NJ, Bell NJ, Shafi NT, Daniels T, Shelmerdine S, Felton I, Gunaratnam C, Jones AM, Horsley AR. Effects of ivacaftor in patients with cystic fibrosis who carry the G551D mutation and have severe lung disease. Chest 2014;146(1):152-8. doi: 10.1378/chest.13-2397

22. Hebestreit H, Sauer-Heilborn A, Fischer R, Käding M, Mainz JG. Effects of ivacaftor on severely ill patients with cystic fibrosis carrying a G551D mutation. J Cyst Fibros 2013;12(6):599-603. doi: 10.1016/j. jcf.2013.05.006

23. Available at: http://www.drugs.com/uk/kalydeco.html. Accessed the $15^{\text {th }}$ January 2016.

24. Available at: www.sukl.cz/modules/procedures/index.php?data $\% 5 B s p z n \% 5 D=\& d a t a \% 5 B$ name $\% 5 D=K a l y d e c o . ~ A c c e s s e d ~ t h e ~ 15^{\text {th }}$ January 2016. 